\title{
ISOLATION AND CHARACTERISATION OF PORCINE EPIDEMIC DIARRHOEA VIRUS IN HUNGARY - SHORT COMMUNICATION
}

\author{
Anna VALKÓ ${ }^{1 *}$, Ervin AlBERT ${ }^{2}$, Attila CsÁGOlA ${ }^{3}$, Tünde VARGA ${ }^{2}$, Krisztián KIss ${ }^{4}$, \\ Rózsa FARKAS ${ }^{5}$, Zsuzsanna RÓNAI ${ }^{5}$, Imre BIKSI ${ }^{2}$ and Ádám DÁN ${ }^{5}$ \\ ${ }^{1}$ Department of Microbiology and Infectious Diseases, University of Veterinary \\ Medicine Budapest, István u. 2, H-1078 Budapest, Hungary; ${ }^{2}$ Department and Clinic \\ for Production Animals, University of Veterinary Medicine Budapest, Üllő, Hungary; \\ ${ }^{3}$ Ceva-Phylaxia Co. Ltd, Budapest, Hungary; ${ }^{4}$ SCG Diagnosztika Ltd., Délegyháza, \\ Hungary; ${ }^{5}$ National Food Chain Safety Office, Veterinary Diagnostic Directorate, \\ Budapest, Hungary
}

(Received 11 January 2018; accepted 2 May 2019)

\begin{abstract}
Porcine epidemic diarrhoea virus (PEDV) is an emerging enteropathogen, causing great economic losses in the pig industry. After many years of quiescence, PEDV was detected in Hungary in 2016 with a recombination in its $\mathrm{S}$ gene. In order to determine the extent of this change, an attempt was made to isolate the recombinant PEDV. This study was extended with a variety of samples collected from three separate farms with newly identified PEDV in 2018. The recombinant PEDV from 2016 was isolated successfully along with three viruses from 2018, and one isolate from the new cases was used for whole genome determination. Whole genome sequence alignment revealed the highest identity with recombinant Hungarian and Slovenian PEDV within the low-pathogenic European viruses. This suggests that these recombinant PEDV are circulating in this area and may spread to other parts of the continent.
\end{abstract}

Key words: Porcine epidemic diarrhoea virus, isolation, full genome, recombination

Enteric diseases induced by viruses are highly prevalent and have great economic importance in the swine industry (Zhang et al., 2013). Nowadays one of the most important enteropathogenic agents is porcine epidemic diarrhoea virus (PEDV), which is a coronavirus possessing an approximately 28-kb-long positive-sense, single-stranded RNA genome (Woo et al., 2010). PEDV was first discovered in the 1970s in England and became a regular cause of diarrhoea in swine, but was reduced to sporadic cases in Europe at the end of the 20th century (Pensaert and Martelli, 2016). In contrast, PEDV is still the main pathogen asso-

*Corresponding author; E-mail: valko.anna@univet.hu; Phone: 0036 (1) 251-9900; Fax: 0036 (1) 251-9260 
ciated with enteric diseases in Asia since its first detection (Wang et al., 2018). At the beginning of this decade, severe outbreaks caused by highly pathogenic variants occurred in China (Li et al., 2012). In 2013, genetically similar virulent PEDV appeared in North America that had been free from this disease previously (Huang et al., 2013). At the same time, clinically milder variants were also identified and named S INDEL strains based on the insertions and deletions in their S gene compared to the highly virulent non-S INDEL viruses (Vlasova et al., 2014). Currently both strains are circulating in the United States, while there are only a few cases in Europe.

In 2016, an outbreak with low mortality occurred in Hungary, where a virus generally similar to recent European PEDVs with a recombination in its $\mathrm{S}$ gene was found (Valkó et al., 2017). The reported recombination event involved a swine enteric coronavirus ( $\mathrm{SeCoV})$, which possesses the $\mathrm{S}$ gene from PEDV within a backbone of transmissible gastroenteritis virus (TGEV) (Belsham et al., 2016). After this outbreak an attempt was made to isolate this recombinant virus and to search for PEDV in other farms with diarrhoea throughout the country.

PEDV was confirmed with real-time PCR using Viroreal Kit PEDV\&SDCV (Ingenetix GmbH, Vienna, Austria) in three distinct Hungarian farms in 2018, involving a farrow-to-finish pig farm (Farm A) and two fattening operations (Farms B and C). Morbidity of suckling piglets reached 100\%, while mortality peaked at $40 \%$ among piglets less than one week old in Farm A. Lack of appetite and grey skin tone were typical signs in weaned pigs and fatteners resulting in a considerable setback of weight gain, even though diarrhoea was apparent in only about $10 \%$ of the animals. Rectal and environmental swabs, intestines, faeces, and blood samples were collected from eight boars, sows, gilts, four- and oneweek-old piglets, respectively. Clinical signs of diarrhoea and considerable weight variability in pigs were observed in Farm B. Vomiting was not noticed and no mortality occurred. Rectal and environmental swabs, oral fluid and blood samples were collected from five different pigsties. Six carcasses of pigs with a weight range of 21 to $68.5 \mathrm{~kg}$ were sent for routine pathological examinations from Farm $\mathrm{C}$ without further information provided.

Virus isolation was attempted from an intestinal sample containing HUN/ 5031/2016 (Accession No. KX289955) along with 16 PCR-positive (oral fluid, intestinal content, rectal swab and faecal) samples from the three farms. The methods described by Chen et al. (2014) were used with slight modifications. Vero cells were cultured and maintained in Dulbecco's Modified Eagle Medium (DMEM) supplemented with $10 \%$ fetal bovine serum (FBS) and $5 \%$ antibiotic/antimycotic $100 \times$ (Biowest, France). Confluent Vero cells on $25-\mathrm{cm}^{2}$ flasks were washed with phosphate-buffered saline (PBS) and inoculated with $200 \mu 1$ sample and $7 \mathrm{ml}$ postinoculation medium, which did not contain FBS but was supplemented with $10 \mu \mathrm{g} / \mathrm{ml}$ trypsin compared to the maintenance medium. Inoculated cells were incubated at $37{ }^{\circ} \mathrm{C}$ with $5 \% \mathrm{CO}_{2}$ and were checked daily for 
cytopathogenic effect (CPE). All flasks were frozen and thawed three times on the seventh or earlier day depending on the appearance of CPE. The tissue culture fluids were examined for the presence of PEDV $\mathrm{N}$ gene as described previously (Li et al., 2013).

A new virus isolate named HUN/S236/2018 was used for full-length genome determination. PCR was performed as described previously (Song et al., 2015). All PCR products were submitted to BaseClear B.V. (Leiden, The Netherlands) or to Biomi Ltd. (Gödöllő, Hungary) for sequencing in both directions by Sanger methodology. Sequences were edited, analysed and the complete genome was assembled with DNASTAR software version 15.2 (DNASTAR, Inc., Madison, Wisconsin, USA). The complete genome sequence was submitted to GenBank under the accession number MH593900. Alignments of HUN/S236/2018 strain along with PEDV sequences retrieved from GenBank were built and a phylogenetic tree (Fig. 1) was computed using the software MEGA version 6.0 (Tamura et al., 2013). Aligned sequences were edited and analysed by using BioEdit version 7.2.5 (Ibis Biosciences, Carlsbad, California, USA). Recombination was analysed by using the RDP4 package (Martin et al., 2015).

Virus isolation was successful from the intestinal sample containing the already sequenced virus HUN/5031/2016 (Accession No. KX289955) and from three novel intestinal content samples from Farm C.

The isolate HUN/S236/2018, producing the largest amount of amplicons in the N-gene-specific PCR was chosen for full-length genome analysis. The full genome sequence of this new Hungarian isolate with a length of 28,009 base pairs and $41.85 \% \mathrm{G}+\mathrm{C}$ content shared the highest identity of $99.6 \%$ with HUN/5031/2016 (Accession No. KX289955) and SLOreBAS-1/2015 (Accession No. KY019623). In phylogeny reconstruction, it appeared in the clade of other recently detected S INDEL PEDVs (Fig. 1).

Similar results were found at the S gene level, where the highest identity with the aforementioned two PEDVs was $99.5 \%$, while it did not reach $99 \%$ with other viruses. Focusing on the section between positions 248 and 640, where a recombination event was found in HUN/5031/2016 (Valkó et al., 2017), the identity between the two Hungarian strains reached 99.1\%. A somewhat lower sequence identity (of 98.8\%) was observed with two Slovenian recombinant PEDVs (Accession No. KY019623 and KY019624), while sequence identities of only 96.1\% were found with a SeCoV from Slovakia (Accession No. KX689261), 95\% with SeCoVs from Italy (Accession No. KR061459) and Germany (Accession No. LT545990), and about 89\% with other European PEDVs. Recombination was verified by several detection methods and the minor parent contributing the smaller fraction of the sequence was identified as SeCoV Italy/213306/2009 (Accession No. KR061459), while the major parent remained unknown.

Previously, only a single PEDV outbreak had occurred in a small farrowto-finish farm in Hungary in 2016. No additional cases have been reported ex- 
cept these three confirmed outbreaks in 2018. Moreover, interestingly, no coronaviruses were found either during our recent survey conducted in 2016-2018 to assess the frequency of different viruses in porcine diarrhoea cases in Hungary (Valkó et al., 2019).

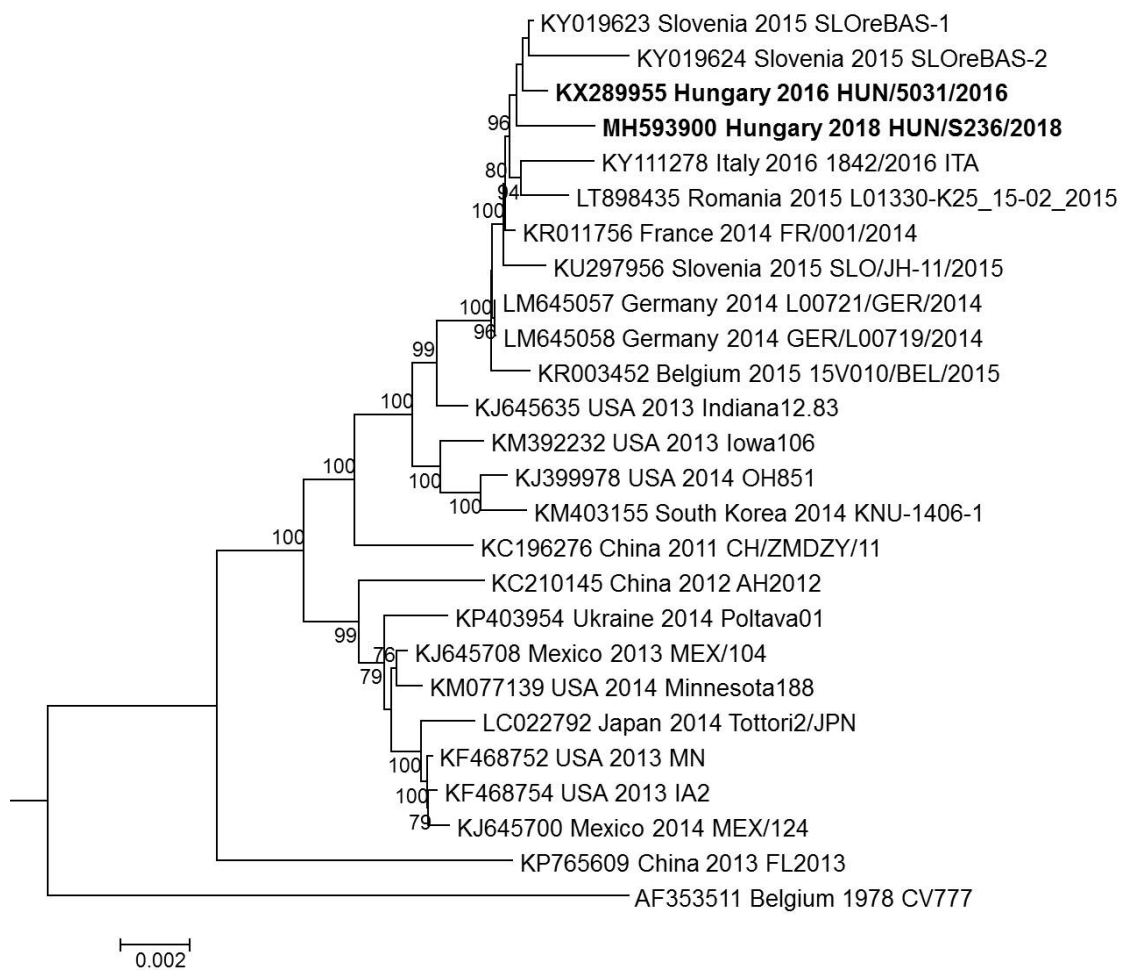

Fig. 1. Neighbour-joining phylogenetic tree computed with MEGA6 using the Maximum Composite Likelihood method based on full-length genome alignment of multiple PEDV sequences downloaded from GenBank. Bootstrap values calculated on 1000 replicates above $70 \%$ are indicated along the branches. Scale bar indicates nucleotide substitutions per site. Accession number, country, year of detection and the name of each virus are shown. Hungarian PEDV strains are indicated in bold

The possible source of the infection is unclear. The farm that had experienced PED in 2016, terminated operation after the clinical signs had ceased, therefore its role in the recent cases is unlikely. Farm A imported boars a few weeks before the clinical onset of the disease, and boars may transfer PEDV with their semen as well (Gallien et al., 2018). However, there was no outbreak on the exporting farm and the results of the molecular biological examinations did not support this introduction route either. Farms A and B are connected through the same slaughterhouse, so transport vehicles might have had a role in the spread of the infection. Neither farms are connected to Farm C, where potential introduc- 
tion routes were not investigated thoroughly, as the owner of the farm rejected further co-operation after the initial diagnosis had been made.

Besides the earlier sequenced virus, three additional strains were isolated from samples of Farm C. Two recombinant strains of PEDV from pigs with diarrhoea from Slovenia shared the highest sequence identity with our newly isolated strain. No further data concerning the recombination event or details on the disease outbreak in Slovenia have been published yet. Based on the GenBank records, these Slovenian viruses were identified in samples collected prior to the Hungarian outbreak in 2016, which suggests that the recombinant virus appeared in Slovenia first. We assume that these recombinant viruses started to circulate in the adjacent areas, resulting in their reappearance in Hungary in 2018 and their introduction to Italy, where these variants became dominant by 2017 (Boniotti et al., 2018).

Based on the phylogenetic analysis of whole genome sequences, PEDVs can be divided into two genogroups, G1 and G2. Low pathogenic S INDEL PEDVs form a distinct subgroup within G2, including American and European viruses (Pizzurro et al., 2018). PEDV HUN/S236/2018 grouped together with these S INDEL viruses along with SLOreBAS-1/2015 (Accession No. KY019623), as shown in Fig. 1. Analysis of the S gene showed similar results, although the recombinant section had higher identity with a SeCoV detected in Slovakia in 2015 (Mandelik et al., 2018), even though the minor parent was identified as an Italian $\mathrm{SeCoV}$ (Accession No. KR061459). Detection of new SeCoV in the area should clarify the origin of the novel recombinant PEDV isolated by us.

Low pathogenic PEDVs appear to be circulating in Europe, as only one case of PED with high mortality occurred in Ukraine in 2015 (Dastjerdi et al., 2015). However, the appearance of further genetic variations should be expected, as coronaviruses are especially prone to mutations and recombination leading to changes in the clinical severity of the disease as well (Su et al., 2016). For studying the connection between genetic changes and the pathogenesis, the isolation and in vitro propagation of the viruses would be indispensable, although this has proved to be a challenge regarding PEDV (Chen et al., 2014). To the best of our knowledge, only two strains have been isolated to date in Germany among recently detected European PEDVs, but neither of them is a recombinant (Hanke et al., 2015). Further experiments with our recombinant isolates might help to elucidate whether the changes in that specific region of the $\mathrm{S}$ gene can influence the pathogenesis of PEDV, for example through altered receptor binding.

\section{Acknowledgement}

The authors would like to thank field veterinarian Róbert Turi for providing samples and epizootiological information concerning Farm A. 


\section{References}

Belsham, G. J., Rasmussen, T. B., Normann, P., Vaclavek, P., Strandbygaard, B. and Bøtner, A. (2016): Characterization of a novel chimeric swine enteric coronavirus from diseased pigs in Central Eastern Europe in 2016. Transbound. Emerg. Dis. 63, 595-601.

Boniotti, M. B., Papetti, A., Bertasio, C., Giacomini, E., Lazzaro, M., Cerioli, M., Faccini, S., Bonilauri, P., Vezzoli, F., Lavazza, A. and Alborali, G. L. (2018): Porcine epidemic diarrhoea virus in Italy: Disease spread and the role of transportation. Transbound. Emerg. Dis. 65, 1935-1942.

Chen, Q., Li, G., Stasko, J., Thomas, J. T., Stensland, W. R., Pillatzki, A. E., Gauger, P. C., Schwartz, K. J., Madson, D., Yoon, K.-J., Stevenson, G. W., Burrough, E. R., Harmon, K. M., Main, R. G. and Zhang, J. (2014): Isolation and characterization of porcine epidemic diarrhea viruses associated with the 2013 disease outbreak among swine in the United States. J. Clin. Microbiol. 52, 234-243.

Dastjerdi, A., Carr, J., Ellis, R. J., Steinbach, F. and Williamson, S. (2015): Porcine epidemic diarrhea virus among farmed pigs, Ukraine. Emerg. Infect. Dis. 21, 2235-2237.

Gallien, S., Moro, A., Lediguerher, G., Catinot, V., Paboeuf, F., Bigault, L., Berri, M., Gauger, P. C., Pozzi, N., Authié, E., Rose, N. and Grasland, B. (2018): Evidence of porcine epidemic diarrhea virus (PEDV) shedding in semen from infected specific pathogen-free boars. Vet. Res. 49, 7-16.

Hanke, D., Jenckel, M., Petrov, A., Ritzmann, M., Stadler, J., Akimkin, V., Blome, S., Pohlmann, A., Schirrmeier, H., Beer, M., and Höper, D. (2015): Comparison of porcine epidemic diarrhea viruses from Germany and the United States, 2014. Emerg. Infect. Dis. 21, 493-496.

Huang, Y.-W., Dickerman, A. W., Pineyro, P., Li, L., Fang, L., Kiehne, R., Opriessnig, T. and Meng, X.-J. (2013): Origin, evolution, and genotyping of emergent porcine epidemic diarrhea virus strains in the United States. MBio 4, e00737-13.

Li, W., Li, H., Liu, Y., Pan, Y., Deng, F., Song, Y., Tang, X. and He, Q. (2012): New variants of porcine epidemic diarrhea virus, China, 2011. Emerg. Infect. Dis. 18, 1350-1353.

Li, Z., Chen, F., Yuan, Y., Zeng, X., Wei, Z., Zhu, L., Sun, B., Xie, Q., Cao, Y., Xue, C., Ma, J. and Bee, Y. (2013): Sequence and phylogenetic analysis of nucleocapsid genes of porcine epidemic diarrhea virus (PEDV) strains in China. Arch. Virol. 158, 1267-1273.

Mandelik, R., Sarvas, M., Jackova, A., Salamunova, S., Novotny, J. and Vilcek, S. (2018): First outbreak with chimeric swine enteric coronavirus (SeCoV) on pig farms in Slovakia - lessons to learn. Acta Vet. Hung. 66, 488-492.

Martin, D. P., Murrell, B., Golden, M., Khoosal, A. and Muhire, B. (2015): RDP4: Detection and analysis of recombination patterns in virus genomes. Virus Evol. 1, vev003.

Pensaert, M. B. and Martelli, P. (2016): Porcine epidemic diarrhea: A retrospect from Europe and matters of debate. Virus Res. 226, 1-6.

Pizzurro, F., Cito, F., Zaccaria, G., Spedicato, M., Cerella, A., Orsini, M., Forzan, M., D’Alterio, N., Lorusso, A. and Marcacci, M. (2018): Outbreak of porcine epidemic diarrhoea virus (PEDV) in Abruzzi region, central-Italy. Vet. Med. Sci. 4, 73-79.

Song, D., Huang, D., Peng, Q., Huang, T., Chen, Y., Zhang, T., Nie, X., He, H., Wang, P., Liu, Q., Tang, Y. and Zhang, Q. (2015): Molecular characterization and phylogenetic analysis of porcine epidemic diarrhea viruses associated with outbreaks of severe diarrhea in piglets in Jiangxi, China 2013. PloS One 10, e0120310.

Su, S., Wong, G., Shi, W., Liu, J., Lai, A. C. K., Zhou, J., Liu, W., Bi, Y. and Gao, G. F. (2016): Epidemiology, genetic recombination, and pathogenesis of coronaviruses. Trends Microbiol. 24, 490-502.

Tamura, K., Stecher, G., Peterson, D., Filipski, A. and Kumar, S. (2013): MEGA6: Molecular Evolutionary Genetics Analysis Version 6.0. Mol. Biol. Evol. 30, 2725-2729. 
Valkó, A., Biksi, I., Cságola, A., Tuboly, T., Kiss, K., Ursu, K. and Dán, Á. (2017): Porcine epidemic diarrhoea virus with a recombinant $\mathrm{S}$ gene detected in Hungary, 2016. Acta Vet. Hung. 65, 253-261.

Valkó, A., Marosi, A., Cságola, A., Farkas, R., Rónai, Z. and Dán, Á. (2019): Frequency of diarrhoea-associated viruses in swine of various ages in Hungary. Acta Vet. Hung. 67, 140-150.

Vlasova, A. N., Marthaler, D., Wang, Q., Culhane, M. R., Rossow, K. D., Rovira, A., Collins, J. and Saif, L. J. (2014): Distinct characteristics and complex evolution of PEDV strains, North America, May 2013-February 2014. Emerg. Infect. Dis. 20, 1620-1628.

Wang, X.-Y., Ji, C.-J., Zhang, X., Xu, D.-P. and Zhang, D.-L. (2018): Infection, genetic and virulence characteristics of porcine epidemic diarrhea virus in northwest China. Infect. Genet. Evol. 62, 34-39.

Woo, P. C. Y., Huang, Y., Lau, S. K. P. and Yuen, K.-Y. (2010): Coronavirus genomics and bioinformatics analysis. Viruses 2, 1804-1820.

Zhang, Q., Hu, R., Tang, X., Wu, C., He, Q., Zhao, Z., Chen, H. and Wu, B. (2013): Occurrence and investigation of enteric viral infections in pigs with diarrhea in China. Arch. Virol. 158, 1631-1636.

This is an open-access article distributed under the terms of the Creative Commons Attribution 4.0 International License (https://creativecommons.org/licenses/by/4.0/), which permits unrestricted use, distribution, and reproduction in any medium, provided the original author and source are credited, a link to the CC License is provided, and changes - if any - are indicated. (SID_1) 